\title{
A Prototype Analysis of Gratitude: Varieties of Gratitude Experiences
}

\author{
Nathaniel M. Lambert \\ Florida State University \\ Steven M. Graham \\ New College of Florida \\ Frank D. Fincham \\ Florida State University
}

The present research tested the hypothesis that concepts of gratitude are prototypically organized and explored whether lay concepts of gratitude are broader than researchers' concepts of gratitude. In five studies, evidence was found that concepts of gratitude are indeed prototypically organized. In Study 1, participants listed features of gratitude. In Study 2, participants reliably rated the centrality of these features. In Studies $3 a$ and $3 b$, participants perceived that a bypothetical other was experiencing more gratitude when they read a narrative containing central as opposed to peripheral features. In Study 4, participants remembered more central than peripheral features in gratitude narratives. In Study $5 a$, participants generated more central than peripheral features when they wrote narratives about a gratitude incident, and in Studies $5 a$ and $5 b$, participants generated both more specific and more generalized types of gratitude in similar narratives. Throughout, evidence showed that lay conceptions of gratitude are broader than current research definitions.

Keywords: gratitude; benefit-triggered gratitude; generalized gratitude; prototype analysis; positive psychology; interpersonal exchange

$\mathrm{T}$ he emergence of positive psychology has focused on several constructs that have received limited attention. One such construct is gratitude. Gratitude appears to have important implications for well-being; it has been shown to predict higher levels of prosocial behavior (McCullough, Kilpatrick, Emmons, \& Larson, 2001) and sense of coherence (Lambert, Graham, Fincham, \& Stillman, in press), and lower levels of posttraumatic stress disorder (Masingale et al., 2001, as cited in Emmons \& McCullough, 2004), decreased materialism (Lambert, Fincham, Stillman, \& Dean, 2009), lower depression (Woodward, Moua, \& Watkins, 1998), and strengthened social bonds (Emmons \& Shelton, 2002; McCullough et al., 2001; McCullough \& Tsang, 2004). Lambert and colleagues (Lambert, Clark, Durtschi, Fincham, \& Graham, 2009; Lambert \& Fincham, 2009) found that participants randomly assigned to express gratitude to a friend twice a week for 3 weeks reported more willingness to voice relationship concerns, had higher positive regard for the friend, and perceived greater communal strength than those in control conditions. Thus, considerable evidence suggests that gratitude is important for psychological well-being.

The potential positive effects of gratitude on individuals and society are numerous and researchers have recently begun to explore them. Along with the burgeoning research on this construct comes the need for greater precision in defining it. The purpose of the present research is to examine how laypersons conceptualize gratitude via prototype analysis. By doing so we intend to gain insight into whether lay concepts of gratitude match those of researchers.

Authors' Note: We thank Tyler Stillman for assistance with data preparation and Olya Lambert, Elaina Plunkett, Andrea Roth, and Melissa Weiler for assistance with the coding. Correspondence concerning this article should be addressed to Nathaniel M. Lambert, Family Institute, Sandels Building, Florida State University, Tallahassee, Florida, 32306; e-mail: nlambert@fsu.edu.

PSPB, Vol. 35 No. 9, September 2009 1193-1207

DOI: $10.1177 / 0146167209338071$

(C) 2009 by the Society for Personality and Social Psychology, Inc. 


\section{How Has Gratitude Been Conceptualized and Defined by Researchers?}

Researchers have variously conceptualized gratitude as a moral virtue, an attitude, an emotion, a habit, a personality trait, and a coping response (Emmons, McCullough, $\&$ Tsang, 2003). Some researchers conceptualize gratitude simply as the recognition that one is the beneficiary of another's kind act. Emmons (2004) defined gratitude as awareness of a gift from another, and Solomon (1977) defined it as awareness of a gain for which someone else is responsible.

However, others have gone beyond viewing gratitude as mere recognition of kindness. For example, Simmel (1908/1950) emphasized that gratitude is also a cognitiveemotional reminder to people of their need to reciprocate. Similarly, Fitzgerald (1998) identified three important components of gratitude that include not only a warm sense of appreciation for something or somebody but also a sense of goodwill toward that thing or person and a resultant disposition to act positively because of appreciation and goodwill.

\section{Discrepancies in Defining Gratitude}

Despite this overlap, there are discrepancies in how scholars define gratitude. Most researchers adopt a narrow definition that reflects a response to an interpersonal benefit transfer (e.g., Emmons, 2004; Roberts, 2004) and may be characterized as being "grateful to someone." Proponents of a broader definition acknowledge this as an important aspect of gratitude yet conceive of gratitude as also appreciating what is valuable and meaningful to oneself, characterized by being "grateful for something or someone" (Adler \& Fagley, 2005; Steindl-Rast, 2004).

The narrow definition. The narrow definition is captured by Roberts's (2004) conceptualization of gratitude as having three major aspects: the benefit, the beneficiary, and the benefactor. Gratitude is experienced when a benefactor provides a benefit to a beneficiary who perceives the benefactor and benefit positively and is willing to be indebted to the benefactor. Most researchers use a similar definition. For example, Guralnik (1971) and Emmons (2004) both define gratitude this way. These definitions suggest that gratitude results from interpersonal exchange.

The broad definition. Steindl-Rast (2004) defines gratitude more broadly as a state of thankfulness. He describes two important aspects of gratitude, one of which he terms personal gratitude, which is similar to Roberts's (2004) definition of gratitude: the sense of appreciation one might experience in the solitude of a mountain top he labels transpersonal gratefulness. He further describes this type of gratitude or gratefulness as a thrill of being, or a "celebration of undeserved kindness" (p. 284). Additionally, the object of celebration may be a thing, a person, an activity, an event, a situation, or a state. One drawback to using the word transpersonal to describe this type of gratitude is that it leaves out a general sense of being grateful for relationships with people in one's life.

Adler and Fagley (2005) also discuss gratitude in a broad sense but call it appreciation. They define appreciation as "acknowledging the value and meaning of something - an event, a person, a behavior, an objectand feeling a positive emotional connection to it" (p. 81).

Conceptual approach used in current research. We define the emotion that results from an interpersonal transfer of a benefit from a beneficiary to a benefactor as being benefit-triggered gratitude, or "grateful to" gratitude. The broader type of gratitude mentioned earlier is expanded to include being grateful for all sorts of gifts in life, including the presence of cherished others in one's life (rather than for particular benefits conferred by those others). We term this generalized gratitude and view it as the emotion or state resulting from an awareness and appreciation of that which is valuable and meaningful to oneself.

Is the distinction drawn between these two types of gratitude evident in lay conceptions of the construct? In addition to testing the hypothesis that gratitude has a prototype structure, a second objective of our research is to determine whether laypeople think of gratitude in terms consistent with benefit-triggered gratitude, generalized gratitude, or both.

\section{Usefulness of Ascertaining the Layperson's Perspective}

There are numerous practical and theoretical considerations that make it important to understand how laypersons conceive of gratitude. The recent growth of research on gratitude is likely to lead to a proliferation of new measures of the construct. Understanding lay concepts of gratitude could facilitate the creation or refinement of such measures. If researchers know how people think about gratitude, this allows them to tailor measures tapping the particular aspects of gratitude that interest them. Thus, the primary purpose of the current studies is to explore lay concepts of gratitude.

Given that the vast majority of research on gratitude is based on self-reports, understanding lay concepts of gratitude-whether narrow or broad-is essential for accurate interpretation of this body of work. To take one example of a recently published finding on gratitude, Andersson, Giacalone, and Jurkiewicz (2007) 
demonstrated that employee feelings of gratitude were associated with greater feelings of social responsibility toward both employer and societal issues. This is an interesting finding with important implications, but what exactly did gratitude mean to the participants in this research? Was it benefit-triggered gratitude employees felt toward their employers for specific benefits that were conferred to them, or was it generalized gratitude that employees felt for the opportunity to work for a particular company in a field they enjoyed? Knowing the type of gratitude involved has important practical implications for research intending to tap into the potential salutary outcomes of gratitude.

As another example, Emmons and McCullough (2003) had participants write down things for which they were grateful. Participants assigned to do so experienced improved psychological well-being relative to those in control conditions. At first glance one might suppose that such an intervention enhanced generalized gratitude; however, it could be that participants also wrote about specific perceived benefits received from others. What was it about the gratitude experienced that led to these improvements? And which type of gratitude-benefit triggered or generalized-is a stronger predictor of these desirable outcomes? A greater understanding of lay concepts would reveal whether both types of gratitude are even represented in how people think about the concept. This could assist future inquiry into the particular aspects of gratitude that are most efficacious in enhancing wellbeing. For example, it might be that getting people to think about others or things for which they are generally grateful is more important than getting people to think about specific benefits for which they are grateful to a benefactor. Enhanced understanding of these different aspects of gratitude could lead to greater understanding of the specific psychological mechanisms involved in the impact of gratitude on well-being.

At a practical or applied level there are also important implications. For instance, Emmons and McCullough's (2003) research suggests that gratitude exercises could fruitfully be applied in psychotherapy. However, to maximize this potential, it is critical to determine whether there are aspects of gratitude that people find negative to avoid iatrogenic effects. This may be a real possibility as previous researchers have discussed indebtedness, an unpleasant state, as being a feature of gratitude (Tesser, Gatewood, \& Driver, 1968). It is important to know whether this or other unpleasant states occur frequently in lay concepts of gratitude so that clinicians can alter instructions to focus on positive aspects of gratitude.

\section{The Prototype Approach}

One effective method of assessing the lay perspective is a prototype approach. In challenging the classical view of concepts, prototype theory has yielded numerous important insights into cognitive and social psychology. According to the classical view, category membership is determined by necessary and sufficient conditions; a case either is or is a not a category member. An implication of this view is that all members of a category are equally representative of that category. Rosch (1975) argued persuasively that many natural language categories do not conform to this classical view. Rather, they are more characteristic of prototypes-a fuzzy collection of features that determine category membership not by complete conformity to necessary and sufficient criteria but rather by possession of many central features of the prototype.

Two conditions must be met for a concept to display a prototype structure (Rosch, 1975). First, people must be able to identify features of the concept and be able to rate their centrality to the concept reliably. Second, the centrality of a given feature should have implications for how one thinks about the relevant concept.

This approach has been influential in social psychology. Beverley Fehr and colleagues have applied the prototype approach to emotion (Fehr \& Russell, 1984; Fehr, Russell, \& Ward, 1982), love (Fehr, 1988, 1994; Fehr \& Russell, 1991), and intimacy in same-sex interactions (Fehr, 2004). Their work shows that these concepts are better characterized as prototypes than as classically defined categories.

It is important to note that prior work has demonstrated that emotion concepts are prototypically organized not only at the superordinate level (e.g., Fehr \& Russell, 1984) but also at more subordinate levels (e.g., Fehr \& Russell, 1991). That is, not only are concepts of the general category emotions prototypically organized, but more specific emotion concepts such as love also are characterized by a prototype structure. This finding supports the plausibility of our prediction that gratitude, a different specific emotion, is prototypically organized.

\section{Overview}

The primary purpose of the current studies was to explore how the layperson perceives the construct of gratitude. We began in Study 1 by obtaining a list of features that laypersons associate with gratitude. In Study 2, we assessed the perceived centrality of each of these features by having another group of participants rate each attribute. We hypothesized that feature centrality would influence the way gratitude was thought about, and in Studies 3a, 3b, and 4 we tested this hypothesis. In these studies we also had participants rate how grateful a hypothetical person was in both a benefittriggered gratitude scenario and a generalized gratitude scenario to determine whether generalized gratitude was included in participants' gratitude constructs. Finally, in 
Studies $5 \mathrm{a}$ and $5 \mathrm{~b}$ we asked participants to generate examples of gratitude to determine whether these examples would (a) contain more central than peripheral features and (b) describe experiences of both benefittriggered and generalized gratitude, respectively.

\section{STUDY 1: COMPILATION OF PROTOTYPIC GRATITUDE FEATURES}

The first step in prototype analyses (e.g., Fehr, 1988; Fehr \& Russell, 1984) has been to compile a list of features that individuals see as describing the relevant construct. Accordingly, participants were asked to list gratitude features in a free-response format. Individuals also rated each self-generated feature in terms of its positivity or negativity.

\section{Method}

Participants. Participants were 94 undergraduate students ( 77 female) participating in exchange for partial class credit. Participants ranged in age from 18 to 30 with a median age of 21 .

Procedure. Participants were given the following instructions (adapted from Fehr \& Russell, 1984, Study 6):

This is a study on the characteristics and attributes that people think of when they think of the word gratitude. For example, if you were asked to list the characteristics of a person experiencing fear, you might write: possible danger occurs, attention is focused on the threat, heart beats wildly, the person runs as fast as they can. In the current study, we are not interested in attributes of fear but in attributes of gratitude. Imagine that you are explaining the word gratitude to someone who has no experience of gratitude. Include the obvious. However, try not to just free-associate. We're interested in what is common to instances of gratitude. Remember that these attributes can be positive or negative.

Participants were then instructed to write down characteristics that come to mind when they hear the word gratitude. They also rated the positivity or negativity of each feature on a 6 -point scale $(1=$ very negative to $6=$ very positive).

\section{Results}

We compiled a verbatim list of all features. We then grouped these features into larger categories adapting Fehr's (1988) procedure, which was adapted from that of Rosenberg and colleagues (Rosenberg \& Jones, 1972; Rosenberg \& Sedlak, 1972). The first step was to extract all monoleximic items, such as thankful, which were easily identified as distinctive features of gratitude. In some cases a participant used a phrase, necessitating judgment of whether the phrase contained one or more distinctive linguistic units (features). Attributes that were preceded by modifiers were coded as a single attribute (e.g., very thankful). The total number of linguistic units extracted through this process was 760 , and each participant generated an average of 8.35 features.

The next step was to place linguistic units into attribute categories. Two research assistants independently assigned each of the 760 features into these attribute categories. Linguistic units were judged to be in the same category if they were (a) different forms of the same word, (b) modified by adjectives or adverbs such as very, or (c) judged to be similar in meaning. Throughout this process coders were conservative to allow unique concepts to emerge; however, at the same time they sought to reduce redundancy. For example, "willingness to sacrifice" was collapsed into the category selfless, and "chances, be it first or second [sic]," was collapsed into the category opportunity. Interrater reliability was assessed with Cohen's Kappa, which takes into account chance agreement. Agreement was acceptable at $\mathrm{K}=.73$. Discrepancies between coders were resolved by a third coder.

This coding procedure resulted in a total of 219 gratitude attributes. Of these attributes, 167 were listed by 2 or fewer participants. Examples of such items were tipping at a restaurant and crying. These responses were removed, leaving a total of 52 gratitude features (see Table 1).

Not surprisingly, gratitude features were overwhelmingly perceived as positive $(M=5.16, S D=1.08)$. Some examples of the most positive items included compassion, hugging, and happy feeling. Some of the most negative items included jealousy/envy, not common, and knowing what others don't have.

\section{Discussion}

Emmons et al. (2003) described several ways gratitude has been conceptualized, including as a moral virtue, an attitude, an emotion, and a personality trait. We found at least some evidence for each of these conceptualizations. For instance, some participants listed reinforcement of good behavior or helping someone, both of which seem to support the moral virtue concept. Others wrote maintaining a positive attitude, which seems to indicate that several perceive gratitude as an attitude. Emotions, such as warm feeling, peacefulness, or happy feeling, were frequently mentioned as were words that would point toward gratitude being a personality trait, such as generous, loving, and bumble. In addition, several respondents listed actions or behaviors such as saying 
TABLE 1: Gratitude Features (in Order of Study 2 Centrality Rankings)

\begin{tabular}{|c|c|c|c|c|}
\hline \multirow[b]{2}{*}{ Central Feature } & \multicolumn{2}{|c|}{ Study 1} & \multicolumn{2}{|c|}{ Study 2} \\
\hline & $\begin{array}{c}\% \text { of } \\
\text { Participants }\end{array}$ & $\begin{array}{c}\text { Positivity } \\
\text { Rating }\end{array}$ & $\begin{array}{c}\text { Centrality } \\
\text { Rating }\end{array}$ & $S D$ \\
\hline Appreciation & 60.43 & 5.75 & 7.46 & 0.95 \\
\hline Thankful & 72.53 & 5.82 & 7.38 & 1.09 \\
\hline Grateful & 18.68 & 5.94 & 7.37 & 0.98 \\
\hline \multicolumn{5}{|l|}{ Expressing thanks/ } \\
\hline "thank you" & 13.19 & 5.43 & 7.17 & 1.18 \\
\hline Family & 8.79 & 5.75 & 7.15 & 1.17 \\
\hline Sincerity & 5.49 & 5.80 & 7.13 & 1.15 \\
\hline Helping someone & 15.39 & 5.71 & 7.10 & 1.23 \\
\hline Graciousness & 5.49 & 5.80 & 7.07 & 1.07 \\
\hline Happy feeling & 40.86 & 5.94 & 7.02 & 1.09 \\
\hline Respectful & 9.89 & 5.44 & 7.02 & 1.22 \\
\hline Giving & 12.09 & 5.36 & 6.98 & 1.35 \\
\hline Nice/kind & 23.08 & 5.63 & 6.97 & 1.24 \\
\hline Warm feeling & 13.19 & 5.31 & 6.97 & 1.06 \\
\hline Being caring & 16.48 & 5.50 & 6.92 & 1.30 \\
\hline Loving & 19.78 & 5.77 & 6.91 & 1.48 \\
\hline Compassion & 6.59 & 6.00 & 6.88 & 1.37 \\
\hline Honor & 3.30 & 6.00 & 6.83 & 1.29 \\
\hline Considerate/ thoughtful & 8.79 & 5.22 & 6.82 & 1.24 \\
\hline Smiles & 13.19 & 5.75 & 6.78 & 1.36 \\
\hline Honest & 3.30 & 4.67 & 6.75 & 1.26 \\
\hline \multicolumn{4}{|l|}{ Maintaining a positive } & 1.41 \\
\hline Praise & 5.49 & 5.80 & 6.70 & 1.81 \\
\hline Generous & 3.30 & 5.33 & 6.70 & 1.45 \\
\hline Humble & 6.59 & 4.67 & 6.65 & 1.30 \\
\hline Hugging & 3.30 & 6.00 & 6.56 & 1.36 \\
\hline Friends & 9.89 & 5.56 & 6.55 & 1.59 \\
\hline Emotions & 3.30 & 5.00 & 6.54 & 1.38 \\
\hline Enhances self-esteem & 3.30 & 6.00 & 6.45 & 1.52 \\
\hline Pleasant & 3.30 & 5.67 & 6.38 & 1.38 \\
\hline Satisfaction & 17.58 & 5.79 & 6.37 & 1.53 \\
\hline Opportunity & 6.59 & 5.50 & 6.33 & 1.46 \\
\hline \multicolumn{2}{|l|}{ Reciprocation of favor/ } & 5.18 & 6.30 & 1.72 \\
\hline \multicolumn{4}{|l|}{ Reinforcement of } & 1.66 \\
\hline \multicolumn{5}{|l|}{ Triggered by } \\
\hline support or help & 13.19 & 4.63 & 6.23 & 1.53 \\
\hline Enthusiasm & 4.40 & 5.00 & 6.19 & 1.39 \\
\hline Peacefulness/calm & 4.40 & 6.00 & 6.19 & 1.64 \\
\hline Selflessness & 9.89 & 5.27 & 6.13 & 2.29 \\
\hline Recognition & 12.89 & 5.31 & 6.06 & 1.83 \\
\hline Awareness & 7.69 & 5.25 & 5.96 & 1.83 \\
\hline Prayer & 3.30 & 6.00 & 5.76 & 2.16 \\
\hline Send a card & 4.40 & 6.00 & 5.73 & 1.83 \\
\hline Deeds & 3.30 & 5.00 & 5.65 & 1.90 \\
\hline Religion/God & 7.69 & 5.14 & 5.52 & 2.16 \\
\hline Receiving a present & 5.49 & 5.50 & 5.16 & 2.00 \\
\hline Feeling luck & 4.40 & 5.00 & 4.92 & 2.19 \\
\hline Money & 3.30 & 5.00 & 5.65 & 1.90 \\
\hline \multicolumn{5}{|l|}{ Knowing what others } \\
\hline don't have & 3.30 & 3.00 & 4.47 & 2.17 \\
\hline Indebtedness & 4.40 & 4.00 & 4.25 & 2.12 \\
\hline Not common & 3.30 & 1.66 & 4.03 & 2.15 \\
\hline Obligation & 4.40 & 2.00 & 3.89 & 2.05 \\
\hline Crying & 3.30 & 3.67 & 3.71 & 1.87 \\
\hline Jealousy/envy & 7.69 & 1.14 & 1.98 & 1.45 \\
\hline
\end{tabular}

"thank you" or reciprocation of a favor or gift. Thus, our findings support the assertion that gratitude is perceived as having aspects of virtue, attitude, emotion, and personality traits.

Although several responses confirmed that laypersons agree with the traditional narrow, benefit-triggered definition of gratitude, quite a few responses give support for a broader definition of gratitude. For example, several respondents listed features such as knowing what others don't have or opportunity, which are clearly generalized gratitude features. Other participants listed family, friends, and God, which are ambiguous features because in addition to being generally grateful for having these relationships, an individual may be grateful to family, friends, or God for specific conferred benefits. Overall, this suggests that at least some individuals think of gratitude as consisting of more than benefittriggered gratitude.

\section{STUDY 2: CENTRALITY RATINGS OF GRATITUDE FEATURES}

To demonstrate that a concept is characterized by a prototypical structure, individuals must be able to indicate which features are more central or more peripheral to that structure. If a concept truly has a prototypical structure, raters should exhibit considerable agreement with one another in their centrality ratings. We therefore conducted Study 2 to determine whether raters would agree over feature centrality.

\section{Method}

Participants. Participants were 91 undergraduates ( 57 female) participating in exchange for partial course credit. Participants ranged in age from 18 to 29 with a median age of 20 .

Procedure. Participants were given the following instructions:

In a previous study, we asked people to tell us their views of gratitude. Specifically, we asked them to "list the characteristics or attributes of gratitude that come to mind." Below are the responses of some of the people in our earlier study. Please read each of the descriptions of gratitude below. After you have read each one, please rate how central or important you think each of the features is to the concept of gratitude.

Participants then rated the centrality of each feature to their concept of gratitude on an 8-point scale ( $1=n o t$ at all central to $8=$ extremely central). To ensure that the order of presentation did not affect ratings, features were presented in one of two random orders. 


\section{Results}

Mean centrality ratings for the 52 features are listed in Table 1. Two indices provided evidence for the reliability of these means. First, the intraclass correlation coefficient (ICC), which is equivalent to the mean of all possible split-half correlations of the 91 judges with respect to the 52 features (ICC $=.94, p<.001)$, was high. Further analyses, based on a flipped data matrix and treating the 52 features as cases and the 91 participants as items, show that the internal consistency of the ratings was exceptionally high $(\alpha=.97)$.

In comparing the centrality ratings of Study 2 with the frequency scores from Study 1 we noted that the two were positively correlated $(r=.38, p<.001)$. For example, the second most highly mentioned feature (listed by $60 \%$ of Study 1 participants), appreciation, received the highest centrality rating by Study 2 participants $(M=7.46$ out of 8 ). In addition, centrality ratings correlated even more highly with positivity $(r=.84, p<.001)$, suggesting that gratitude concepts are primarily positive.

\section{Discussion}

It is noteworthy that participants considered some features to be more prototypical of gratitude than others and that they exhibited a high level of agreement. The fact that participants found the task meaningful fulfills the first criterion for demonstrating that a concept is prototypically organized. Another important finding was that feature centrality was associated with feature positivity. This suggests that, not surprisingly, positive features are more representative of gratitude than are negative features. Also, the correlation between frequency and centrality indicates that the features that first come to mind are often the most central.

Several features that participants perceived as being most central were synonyms of gratitude, such as appreciation. Other central features included attributes that elicited gratitude, such as generous or nice/kind, and results of experiencing gratitude such as smiles or expressing thanks.

\section{STUDY 3a: FEATURE CENTRALITY AND PERCEPTIONS OF GRATITUDE}

The central purpose of Study 3a was to determine whether feature centrality would influence cognition about gratitude, another criterion to demonstrate that a concept has a prototype structure. Specifically, we tested whether the centrality of words used in describing a gratitude experience would influence participants' perception of the level of gratitude experienced. We hypothesized that if central features are more representative of gratitude than peripheral features, participants would perceive that a person experienced more gratitude when the situation was described using central as opposed to peripheral features. A second objective of this study was to determine whether participants perceived instances of both generalized and benefit-triggered gratitude as gratitude-inducing.

\section{Method}

Participants. Participants were 107 undergraduates (81 female) participating in exchange for partial course credit. Participants ranged in age from 18 to 30 with a median age of 21 .

Procedure. We conducted a median split of the centrality ratings to divide traits into central and peripheral traits. Although necessary for present purposes, we acknowledge that such a division is artificial and that centrality is continuous rather than dichotomous.

Participants read two scenarios, one of which described a gratitude experience using only central words and another that included only peripheral words in describing a gratitude experience (see Appendix A for examples). The mean centrality score for all of the central features was 5.63 and the mean centrality score for all of the peripheral words was 5.09. Participants were then asked to rate how closely each scenario matched their concept of gratitude using a 10 -point scale $(1=n o t$ at all to $10=$ extremely).

To examine whether participants perceived generalized gratitude, in addition to benefit-triggered gratitude, as being relevant to their gratitude concepts, we crafted two scenarios: one exemplifying benefit-triggered gratitude and the other exemplifying generalized gratitude. Participants were randomly assigned to condition. To ensure that the centrality of the words used, rather than the content of scenario, accounted for any potential variance between conditions, the scenarios were presented such that each gratitude experience contained central words for one condition of participants and peripheral words for the other condition of participants. We predicted that participants would perceive a person as more grateful in the benefit-triggered gratitude scenarios but would also perceive gratitude in the generalized scenarios.

\section{Results}

Perceptions of gratitude. To assess the impact of feature centrality on participants' perceptions of how much gratitude a hypothetical individual was experiencing, we used the general linear model (GLM) factorial procedure with repeated measures. Centrality (central vs. peripheral) was entered as a within-subjects factor and 
sex (male vs. female) was entered as a between-subjects factor. Because sex did not significantly interact with centrality or significantly affect significance levels for either hypothesis, it was dropped from the analysis presented. ${ }^{1}$ Also, inasmuch as two separate scenarios were presented, we checked for mean differences in scores on the two scenarios, and the mean scores differed significantly. Therefore, we included this as a between-subjects factor. Because it did not significantly alter the results, we dropped it from reported analyses.

As anticipated, a significant main effect for centrality was obtained, $F(1,101)=8.52, p<.001, \eta^{2}=.078$. The scenarios containing central words received an average gratitude rating of 8.50 (using a 10-point scale), and scenarios containing peripheral words received an average gratitude rating of 7.80 , suggesting that trait centrality does indeed affect perception of the construct.

Benefit-triggered versus generalized gratitude. The two scenarios used in Study 3a were carefully crafted so that one would be prototypical of benefit-triggered gratitude and one would be prototypical of generalized gratitude. In so doing we intended to determine whether participants' mean gratitude rating in the benefit-triggered and generalized gratitude scenarios was significantly greater than .5 point above the midpoint on the scale (6). (We chose this more conservative value because the true scale midpoint of 5.5 was not an option for respondents.) Results showed that the ratings were indeed higher for both generalized and benefit-triggered gratitude scenarios. The targets' gratitude level in the benefit-triggered gratitude scenario was $M=8.31$, which was significantly different from $6, t(101)=9.11$, $p<.001$. Similarly, the mean score in the generalized gratitude scenario $(M=7.99), t(101)=8.12, p<.001$, differed significantly from 6 .

We also tested for between-group differences in the responses of participants to the benefit-triggered and generalized gratitude scenarios using a GLM general factorial procedure with repeated measures. The scenarios were counterbalanced, and there was no significant effect based on presented order. The mean rating of gratitude in the benefit-triggered gratitude scenario was significantly higher than in the generalized gratitude scenario, $t(101)=9.03, p<.01$.

\section{Discussion}

Results confirmed our prediction that people think of gratitude as being more than benefit-triggered gratitude. More specifically, when they read about a person in a generalized gratitude situation, they rated that person as experiencing gratitude at a level significantly higher than the scale midpoint. Even without a benefit in the narrative, participants still perceived gratitude. This suggests that lay concepts are not limited to benefittriggered gratitude.

These findings also provide support for our hypothesis that the prototype structure of gratitude affects cognition. Specifically, when participants read a narrative using central gratitude words as opposed to peripheral gratitude words, they rated the target of the narrative as experiencing more gratitude. There were two limitations to this aspect of the study that need to be addressed. First, it could be that asking participants to rate only the amount of gratitude experienced led them to rate the people in the scenarios highly on that dimension. Second, the features included in each scenario differed not only in centrality but also in valence. For example, in one of the pairs of scenarios we used the word obligation in the peripheral scenario, which had a very low valence rating of 2 . This created a gap between the two conditions not only in centrality but in valence (the matching central scenario had a mean valence of 5.68 whereas the relevant peripheral scenario had a mean valence of 4.59). Thus, it could be that valence, rather than centrality, accounted for the observed differences. We conducted Study $3 \mathrm{~b}$ to rule out these two alternative explanations.

\section{STUDY 3b: PERCEPTIONS OF GRATITUDE REVISITED}

To address the limitations of Study 3a, we constructed another test to rule out two plausible alternative explanations. To do so we replicated Study 3a but asked participants to rate three other emotions in addition to gratitude, thus minimizing demand characteristics. Furthermore, we selected features for each scenario that were similar in valence. We hypothesized that the centrality of features would again affect cognition.

\section{Method}

Participants. Participants were 211 undergraduates (187 female) participating in exchange for partial course credit. Participants ranged in age from 17 to 55 with a median age of 20 .

Procedure. Participants read two scenarios, each of which described a gratitude experience. For each participant, one scenario included only central gratitude words and the other included only peripheral gratitude words (see Appendix B). We again used a median split of the centrality ratings to divide traits into central and peripheral traits. The mean centrality rating of the central features was 7.10 and the mean centrality rating of 
the peripheral features was 6.00. This time the mean valences of the features in each condition were virtually identical: The central condition had a mean valence rating of 5.67 and the peripheral condition had a mean valence rating of 5.50. Participants were then asked to rate how well each scenario matched their concept of gratitude using a 15 -point scale $(1=$ not at all to $15=$ perfectly). Participants also rated the happiness, contentment, and satisfaction of the individual in each scenario to reduce the possibility that demand characteristics would lead to high gratitude ratings.

\section{Results}

Perceptions of gratitude. To assess the impact of feature centrality on participants' perceptions of how much gratitude a hypothetical individual was experiencing, we used the GLM factorial procedure with repeated measures. Centrality (central vs. peripheral) was entered as a within-subjects factor, and as anticipated, a significant main effect for centrality was obtained, $F(1,210)=9.26$, $p<.01, \eta_{p}^{2}=.042$. The scenarios containing central words received an average gratitude rating of 13.41 using a 15 -point scale $(1=$ not at all to $15=$ perfectly $)$ and scenarios containing peripheral words received an average gratitude rating of 12.76 .

Benefit-triggered versus generalized gratitude. The two scenarios used in Study 3b were also crafted so that one would be prototypical of benefit-triggered gratitude and one would be prototypical of generalized gratitude. In so doing, we intended to determine whether participants' mean gratitude rating in the benefit-triggered and generalized gratitude scenarios was significantly greater than .5 point above the midpoint on the scale (8). (We chose this more conservative value because the true scale midpoint of 7.5 was not an option for respondents.) Results showed that the ratings were indeed higher for both generalized and benefit-triggered gratitude scenarios. The targets' gratitude level in the benefit-triggered gratitude scenario was $M=12.60$, which was significantly different from 8, $t(222)=23.08, p<.001$. Similarly, the mean score in the generalized gratitude scenario $(M=13.46), t(220)=39.23, p<.001$, differed significantly from 8 .

We also tested for between-group differences in the responses of participants to the benefit-triggered and generalized gratitude scenarios using a GLM general factorial procedure with repeated measures. The scenarios were counterbalanced and there was no significant effect based on presented order. This time the mean rating of gratitude in the generalized gratitude scenario was significantly higher than in the benefit-triggered gratitude scenario, $t(220)=-4.24, p<.01$.

\section{Discussion}

Participants of the current study perceived the person in the generalized gratitude scenario as experiencing significantly more gratitude than the person in the benefittriggered scenario, providing additional evidence that generalized gratitude is an important aspect of the lay conception of gratitude.

The current study provides additional evidence that feature centrality affects cognition. That is, participants perceived more gratitude in a person described in a vignette using central rather than peripheral gratitude words. Additionally, by including ratings other than gratitude, we reduced the possibility that demand characteristics drove the observed effects. Finally, we found no evidence that the effects we observed in Study $3 \mathrm{~b}$ were driven by differences in the valence of the different scenarios. However, despite the fact that the features from Study $3 b$ were matched on valence, this study and Study $3 \mathrm{a}$ are limited in that peripheral features might be more awkwardly worded and it could be that this degree of awkwardness might be confounded with centrality or peripherality. For example, it could be that peripheral terms might result in more clumsy paragraphs. We therefore sought additional evidence that gratitude concepts are characterized by a prototype structure.

\section{STUDY 4: RECOGNITION MEMORY FOR A GRATITUDE NARRATIVE}

In Study 4, we sought to obtain additional evidence for our hypothesis that feature centrality affects cognition. In this study we hypothesized that the prototypic structure of gratitude affects performance on memory recognition tasks related to this construct. The activation of a prototype should result in features closely related to that prototype being more easily accessible in memory than features that are more peripheral in nature (Cantor \& Mischel, 1979). Thus, the objective of Study 4 was to test whether participants would remember more central than peripheral features from a gratitude narrative (both falsely and correctly).

A second objective of the current study was to determine whether participants think that benefit-triggered gratitude is more illustrative of gratitude than is generalized gratitude. Based on the results of Studies 3a and $3 \mathrm{~b}$, we hypothesized that they would but that generalized gratitude would also be illustrative of gratitude to them.

\section{Method}

Participants. Participants were 102 undergraduates (76 female) participating in exchange for partial course 
credit. Participants ranged in age from 18 to 29 with a median age of 20 .

Procedure. Participants read a narrative describing the spring break vacation of two college women that contained three instances of experienced gratitude (to see the full narrative please contact the first author). They were told to read carefully as they would be asked questions about the narrative later in the experiment. Within the narrative we incorporated six central and six peripheral gratitude features. We chose a variety of features so that their average centrality would be representative of their category but would also make sense in the context of the narrative. The average centrality ratings of the central and peripheral features were 7.02 and 5.53 , respectively.

Participants then engaged in an interference activity in which they were asked to write a short paragraph about their daily routine and three things they normally eat in a typical day. They were then asked to write two sentences about what they do during a typical morning, a typical afternoon, and a typical evening.

Next, participants completed the recognition task. They were asked to indicate whether various events had occurred in the gratitude narrative. For example a true statement from the narrative was "Jen's grandma is exceptionally generous" and the parallel false statement was "Jen's grandma is exceptionally selfless." The events consisted of the 12 gratitude features that had been presented in the narrative ( 6 central, 6 peripheral) as well as 12 gratitude features that had not been presented (6 central, 6 peripheral).

Finally, participants were presented with two scenarios, both of which incorporated central words only and were identical to those presented in Study 3a. One scenario described a typical benefit-triggered gratitude situation in which a woman feels grateful to her neighbor for fixing her computer. The other scenario depicted a generalized gratitude scenario, in which a woman feels grateful for the beauty of nature and for her family. Participants were then asked to rate how closely each scenario matched their concept of gratitude using a 7 -point scale $(1=$ not at all to $7=$ very much $)$. They were then asked to rate which scenario most closely matched their concept of gratitude using a 7-point scale ranging from $1=$ Scenario 1 (the benefit-triggered scenario) to $7=$ Scenario 2 (the generalized scenario), with $4=$ midpoint. The scenarios were counterbalanced so that half of the participants rated the scenarios presented in one order and half rated them in reverse order. We hypothesized that benefit-triggered gratitude would be rated as more central to the construct of gratitude but that generalized gratitude would also rate highly.

\section{Results}

Prototype analysis. To assess the impact of feature centrality on participants' perceptions of the narrative, we used the GLM factorial procedure with repeated measures. After conducting the study but before analyzing data, we realized that one event that we had intended to be false used the verb form of a noun that truly did occur in the story (i.e., appreciated vs. appreciation) and that we had mistakenly included one false statement twice. We therefore excluded these events from analyses, resulting in six central and peripheral true statements and five central and peripheral false statements. Analyses including all statements revealed an identical pattern of results, however.

Our first prediction was that for the presented items central features would be correctly recognized more often than peripheral features. As anticipated, a significant main effect for attribute centrality was obtained, $F(1,101)=21.72, p<.001, \eta_{p}^{2}=.177$. An average of $78 \%$ of the six central features was correctly recognized compared with only $65 \%$ of the peripheral features. Our second hypothesis was that participants would be more likely to falsely recognize central features that were not presented than they would be to falsely recognize peripheral features that were not presented. Consistent with this prediction, we obtained a main effect for attribute centrality, $F(1,99)=28.30$, $p<$ $.001, \eta_{p}^{2}=.222$. An average of $44 \%$ central features was falsely recognized compared with only $30 \%$ of peripheral features.

Benefit-triggered versus generalized gratitude. We tested for between-group differences in the responses of participants to the benefit-triggered and generalized gratitude scenarios using a GLM factorial procedure with repeated measures. The scenarios were counterbalanced and there were no significant order effects. As predicted, participants perceived more gratitude in the benefit-triggered than in the generalized scenarios $F(1,104)=18.98, \eta_{p}^{2}=.154, p<.001$. However, both significantly differed from the scale midpoint (4), as the mean score for benefit-triggered gratitude was 5.81, $t(105)=13.53, p<.001$, and the mean score for generalized gratitude was $4.84, t(105)=4.70, p<.001$.

When asked to compare directly which scenario most closely matched their concept of gratitude, participants more frequently chose the benefit-triggered type of gratitude $(M=3.33$ out of 7$)$, which was significantly different from 4 (which would indicate that both scenarios are equal in terms of how well they represent gratitude), $t(106)=-3.62, p<.001$. However, the modal response was 4 , and indeed, a substantial minority $(27 \%)$ considered the generalized scenario as more 
representative of gratitude than the benefit-triggered scenario. This demonstrates that generalized gratitude is likely an important element of the concept of gratitude for participants even if benefit-triggered gratitude is more representative and common.

\section{Discussion}

As in Studies 3a and 3b, we found that the centrality of gratitude features affected cognition for gratitude events. Participants correctly recognized significantly more central than peripheral features. In addition, participants also falsely recognized features that were not presented but were highly central to gratitude, which offers additional support for our hypothesis that central features are more salient in memory than peripheral features.

We also predicted that benefit-triggered gratitude scenarios would be more representative than generalized scenarios but that these generalized scenarios would still be reflective of gratitude. We found support for both predictions. The fact that the modal response for the forced choice question "which scenario better matched your concept of gratitude" was 4 (indicating that the two scenarios "equally" represented participants' conception of gratitude) is important for researchers to note as they collect self-report data on gratitude. The layperson seems to conceive of gratitude as being broader and more complex than researchers typically define it as being.

One limitation of the current study is that we used only one scenario to illustrate each type of gratitude, and this single scenario likely did not fully capture the distinctions between benefit-triggered and generalized gratitude for many participants. Therefore, in Studies 5a and $5 \mathrm{~b}$ we provided an opportunity for participants to generate their own gratitude experiences to determine whether participants would use more central than peripheral features and to assess the degree to which they would write about benefit-triggered gratitude versus generalized gratitude experiences.

\section{STUDY 5a: GENERATION OF GRATITUDE NARRATIVES}

The primary purpose of Study 5 was twofold: we hoped to (a) gain additional evidence to support our previous findings that feature centrality affects cognition and (b) to explore whether the layperson would generate examples of generalized gratitude, in addition to benefit-triggered gratitude, when asked to write about a time when they felt grateful. We predicted that participants would use more central than peripheral features in describing their experience of gratitude. We also hypothesized that participant narratives would include more benefit-triggered gratitude than generalized gratitude experiences but that a substantial minority of individuals would describe generalized gratitude experiences.

\section{Method}

Participants. Participants were 208 undergraduates (157 female) participating in exchange for partial course credit. This sample consisted of the participants from Studies $3 \mathrm{a}$ and 4. Participants completed the narrative task after completing either Study 3a or 4 and then a number of intervening tasks. They ranged in age from 18 to 30 with a median age of 19 .

Procedure. Participants were asked to respond to the following items in a free-response format:

1. Please think back to a time when you felt a great deal of gratitude. Write a paragraph about the experience that made you feel grateful. 2. Specifically, what were some of the thoughts and feelings you had at the time?

3. What were some (if any) of the actions that you took as a result of your thoughts/feelings?

By requesting three responses, we hoped to give features several chances to emerge in the narratives.

\section{Results}

Central and peripheral features. Two research assistants blind to study hypotheses coded the 208 narratives. They were each given a list of the 52 gratitude features generated in Study 1 and were instructed to read each narrative and to list all features mentioned in the narratives. Coders were also instructed to include words that had conceptually similar meaning to 1 of the 52 gratitude features. For instance, several participants mentioned being excited and this was coded as the peripheral feature enthusiasm. We disqualified the frequently mentioned central feature grateful because it was included in the instructions. Given the large number of categories and the fact that we did not limit the number of codes per response, we did not expect an extraordinarily high level of agreement between coders. There was a $63 \%$ agreement rate between coders; however, nearly all of the discrepancies were due to one coder catching codes that the other missed. Discrepancies were resolved by the first author.

To assess the impact of feature centrality on participants' self-generated gratitude experiences, we again used the GLM factorial procedure with repeated measures. Consistent with predictions, participants used more central $(M=2.87)$ than peripheral features $(M=2.28)$ when 
describing their own personal gratitude experience $F(1$, 207) $=14.786, p<.001, \eta_{p}^{2}=.067$.

Benefit-triggered versus generalized gratitude. Once coders had finished coding all narratives for the 52 gratitude features, one blind coder and the second author coded all the narratives as reflecting primarily benefit-triggered gratitude or generalized gratitude or as containing elements of both. Interrater reliability, as established using Cohen's Kappa, was $\mathrm{K}=.72$ and discrepancies between coders were resolved by the first author. The majority of discrepancies between coders $(82 \%)$ were due to one coder seeing descriptions that portrayed only benefit-triggered or generalized gratitude and the other coder seeing both expressed in a single narrative. For example, one participant provided a narrative containing both types of gratitude when describing an experience of feeling grateful to a parent for paying her tuition and for expressing gratitude to have the opportunity to receive an education. Results indicated that $58 \%$ were instances of benefit-triggered gratitude, $22 \%$ were instances of generalized gratitude, and $20 \%$ typified both. Thus, a substantial minority of participants $(42 \%)$ described generalized gratitude in this free-response format.

Some researchers have described the idea of generalized gratitude at the conceptual level but have not provided data to support their theories (e.g., Steindl-Rast, 2004). This study provides evidence for such a conception and illustrates this type of gratitude in the words of the layperson. For our participants, generalized gratitude seemed to be most often elicited by thinking about relationships, adversity, or what they have that others do not. For example, one participant described her experience of feeling generalized gratitude toward her family relationships:

I felt a time of gratitude this summer when my whole family was together. My sister lives in Texas and I live 6 hours away from home, so when we were all together it made me grateful that I have such a good family.

Another participant described feeling generalized gratitude for safety resulting from adversity:

After I was in a bad car accident it made me very grateful to be alive. I could and should have died in the car accident, but God has bigger plans for me, and I'm grateful for a second chance.

This participant mentioned God and this seemed to be a subtheme in the generalized gratitude narratives. These examples illustrate the idea of generalized gratitude from the lay perspective.

\section{Discussion}

Again results confirmed, using a different methodology from Studies 3a, 3b, and 4, that feature centrality affected participants' cognition about gratitude. More specifically, when participants wrote narratives about a time during which they experienced gratitude, they used more central than peripheral features. As expected, these results are further evidence that gratitude has a prototype structure.

The results of Study 5a indicate that a large minority of participants consider generalized gratitude an important component of their gratitude concepts. Also, God appeared as a subtheme in the generalized gratitude narratives. Future research should explore the extent to which the experience and expression of generalized gratitude may relate to views of God.

The example narratives presented earlier illustrate the type of gratitude that was coded as generalized gratitude. Note that none of these responses indicated a specific instance in which a benefit was conferred on them. However, this type of gratitude described by participants in our study has garnered little attention from researchers. In discussing Studies $3 \mathrm{a}$ and 4, we have made a case for thinking more broadly about gratitude, and Study 5a provides additional evidence that this notion is warranted.

One limitation of Study 5a was that the sample was drawn by combining earlier samples of participants that were exposed to scenarios that contained benefittriggered and generalized gratitude concepts. This could have primed participants to consider both types of gratitude in writing their responses to the open-ended questions. However, following this exposure, participants completed 10 measures totaling more than 100 questions. Thus, any potential priming effects had considerable time to decay. Also, it seems unlikely that reading a short scenario would cause a participant to write about a generalized gratitude experience if this were not already part of his or her concept of gratitude. Nonetheless, we sought to address this limitation in Study $5 \mathrm{~b}$.

\section{STUDY 5b: GRATITUDE NARRATIVES REPLICATION}

The objective of Study $5 \mathrm{~b}$ was to replicate the findings of Study 5a with another set of participants. In addition, Study $5 \mathrm{~b}$ addresses the possible alternative explanation that exposure to benefit-triggered or generalized gratitude concepts affected participants' openended responses. This time, participants were not exposed to anything that may have primed either type of gratitude. 


\section{Method}

Participants. Participants were 55 undergraduates (34 female) participating in exchange for partial course credit. Participants ranged in age from 18 to 30 with a median age of 19 .

Procedure. Participants were asked to respond to the following items in a free-response format: "Please think back to a time when you felt a great deal of gratitude. Write a paragraph about the experience that made you feel grateful.”

\section{Results and Discussion}

Two coders-the first author and a blind coder-coded all of the narratives as reflecting primarily benefit-triggered gratitude or generalized gratitude or as containing elements of both. Interrater reliability, as established using Cohen's Kappa was $\mathrm{K}=.91$, and this time discrepancies between coders were resolved by a third coder, blind to the hypothesis of the study. The increased reliability between coders in the current study, compared to that of Study 5a, was likely due to a more thorough explanation of concepts and training of the blind coder.

Results indicated that $53 \%$ were instances of benefittriggered gratitude, $22 \%$ were instances of generalized gratitude, and $25 \%$ typified both. Again, a substantial minority of participants $(47 \%)$ described generalized gratitude in this free-response format. These results closely mirror the results from Study 5a, which suggests that priming is an unlikely alternative explanation for the findings of our previous study. These results replicate prior results in a new sample, providing further evidence that lay concepts of gratitude extend beyond the narrowly construed benefit-triggered gratitude concept.

\section{GENERAL DISCUSSION}

The systematic study of gratitude has emerged in psychology and the way this construct is conceptualized will affect its utility in future research. Our results show that gratitude has a prototypic structure and that the layperson perceives gratitude as more complex than simply an acknowledgment and appreciation of a valued benefit. Given that the majority of research on gratitude is conducted using self-report measures, our documentation of the layperson perspective of gratitude is especially important.

\section{Evidence That Gratitude Is Characterized by a Prototype Structure}

Recall that our primary hypothesis was that lay concepts of gratitude would be characterized by a prototype structure. We based this prediction on Fehr and Russell's findings that conceptions of emotion are prototypically organized at both the superordinate level (Fehr \& Russell, 1984) and the subordinate level (Fehr \& Russell, 1991).

We found substantial evidence across several studies to support this hypothesis. Using features of gratitude identified by participants in Study 1, participants in Study 2 were able to reliably make centrality ratings of these features. This satisfies the first criterion for demonstrating prototype structure. In addition, we found that feature centrality influenced cognition-the second criterion for demonstrating prototype structure. More specifically, in Studies 3a and 3b, participants perceived that a person was experiencing more gratitude when her situation was described with central rather than peripheral features. Furthermore, in Study 4, participants remembered, both correctly and falsely, more central than peripheral features from gratitude narratives. Finally, in Study 5a participants generated narratives about a time when they experienced gratitude in their own lives. Consistent with prototype theory, participants generated more central than peripheral features in these narratives. Collectively, these studies provide compelling evidence that concepts of gratitude, like those of other emotions, are prototypically organized.

\section{Evidence That Lay Constructs of Gratitude Include More Than Benefit-Triggered Gratitude}

Whereas most researchers focus on a relatively narrow view of gratitude, as reflecting the emotion resulting from a benefactor providing a benefit, we found evidence that laypersons think about gratitude more broadly. In Study 1, many participants generated features that are clearly more associated with generalized than with benefit-triggered gratitude such as "knowing what others don't have" and "opportunity."

Providing additional support that people consider generalized gratitude concepts important, participants in Studies 3a and 4 rated scenarios describing a generalized gratitude incident as being consistent with their personal concepts of gratitude (i.e., their ratings were above the scale midpoint). Finally, and importantly, when participants generated their own gratitude narratives in Studies 5a and 5b, many of them described incidents of generalized gratitude. We do not mean to imply that people consider generalized gratitude to be more important than benefit-triggered gratitude; rather, our results suggest that lay concepts of gratitude are not limited to instances of benefit-triggered gratitude.

Of course there may be some benefits to a more narrow definition of gratitude for empirical research. It allows researchers to more precisely define the term and to examine the correlates and consequences of the different 
types of gratitude. However, despite how narrowly researchers may define gratitude for the purposes of a given study, it is important for them to be aware that the layperson may conceive of it more broadly or in a different manner altogether. It is also critically important that their definitions match the ways in which they operationalize the construct.

\section{Synthesizing Definitions With}

\section{Measures and Experimental Inductions}

Despite the limited ways researchers have defined gratitude, the most prominent gratitude measures actually seem to measure both the benefit-triggered and generalized forms of gratitude we have identified. Nonetheless, they lack consistency in how they define gratitude and how they actually measure it. For example, in a manuscript in which they present a widely used gratitude trait measure (the Gratitude Questionnaire [GQ-6], McCullough, Emmons, and Tsang (2002) define gratitude as "a generalized tendency to recognize and respond with grateful emotion to the roles of other people's benevolence in the positive experiences and outcomes that one obtains" (p. 112). This definition is clearly in line with most benefit-triggered gratitude definitions that focus on the bestowal of a benefit on a beneficiary by a benefactor, or an interpersonal exchange. However, several of McCullough et al.'s scale items can clearly be perceived as not including such an interpersonal transfer of a benefit but instead as measuring more generalized gratitude. For example, two of their scale items are "I have so much in life to be thankful for" and "If I had to list everything that I felt grateful for, it would be a very long list." Based on our findings it seems likely that if participants had been asked to write a list of what they were grateful for, generalized gratitude items such as health, family, and education would figure prominently. In fact, Studies $5 \mathrm{a}$ and $5 \mathrm{~b}$ asked a similar openended question and people did describe such items.

Similarly, in their paper on the Gratitude Resentment and Appreciation Test (GRAT) measure, Watkins, Woodward, Stone, and Kolts (2003) used the operational definition of Guralnik (1971) in which he describes grateful affect as being "a feeling of thankful appreciation for favors received" (p. 327). This definition is almost identical to other narrow definitions of gratitude. However, much of Watkins et al.'s GRAT scale does not measure such interpersonal exchanges. Sample items include: "Every Fall I really enjoy watching the leaves change colors" or "I think it's important to sit down every once in a while and 'count your blessings."” Neither of these items appears to measure an interpersonal exchange that would elicit benefit-triggered gratitude. Rather, they are potentially effective items for measuring generalized gratitude.
Researchers should be careful to ensure that their conceptual and operational definitions of constructs match. As has been demonstrated, in the case of gratitude, several current scales of this construct actually measure both benefit-triggered and generalized gratitude. This lack of precision is inimical to theoretical development. Therefore, researchers should either change their conceptual definitions of gratitude to match what they are measuring or create new scales that specifically measure the type of gratitude under study.

\section{Limitations and Future Directions}

Our participants were young, well-educated, mostly single college students, and their conceptions of gratitude may differ from those of older, married, or less educated populations. Given that the objective of this study was to assess the lay perspective of gratitude, the samples from this series of studies assessed only a narrow range of potential participants. Nonetheless, we found it noteworthy that generalized gratitude was so prevalent in such a young population and suspect that it may be even more prevalent in older samples. This could be a fruitful avenue for future research. In addition, gratitude could be conceived of differently in different cultures, and future research should address this possibility.

Inasmuch as the lay perspective of gratitude seems to encompass more than the traditionally employed, narrow definition of gratitude, future research should attempt to clarify this construct. This raises the question of whether researchers should examine these two aspects of gratitude separately. Perhaps future researchers could test whether benefit-triggered gratitude and generalized gratitude are discriminable. One could fruitfully compare the correlates of benefit-triggered gratitude with the correlates of generalized gratitude.

The distinction between two types of gratitude could have important implications for the literature and future research. For instance, in their groundbreaking experiment, Emmons and McCullough (2003) found that participants who kept a gratitude journal reported enhanced mental and even physical health. As part of their experiment they instructed participants: "Think back over the past week and write down on the lines below up to five things in your life that you are grateful or thankful for" (p. 379). Although some benefit-triggered responses may be cited, this exercise would appear to primarily elicit generalized gratitude. How might their results have differed had they instructed participants: "Write down five nice things that people did for you this last week"? We suspect that benefit-triggered gratitude may have stronger implications for interpersonal relationships, whereas generalized gratitude may have stronger implications for personal mental outcomes. Such questions beg to be tested by future research. 


\section{Conclusion}

Research on the construct of gratitude has burgeoned in the last decade, and studies have shown gratitude to be a strong predictor of prosocial behavior, psychological health, and well-being. Despite the recent upsurge of interest in this construct and the large number of researchers who have defined gratitude, no attempts have been made to understand how the layperson perceives this construct. Given that most psychological studies rely on self-reported gratitude, we argue that understanding lay concepts of gratitude is important. Thus, the objectives of the current studies were to establish that the construct of gratitude is prototypically organized and to explore whether the lay concept of gratitude matches how most researchers operationalize gratitude. Study 1 showed that laypersons consider gratitude to have numerous characteristics. In Study 2, participants were able to reliably identify some characteristics as more central than others. Studies $3 a, 3 b$, and 4 demonstrated that feature centrality influenced cognition relating to gratitude. Finally, in Studies $5 \mathrm{a}$ and $5 \mathrm{~b}$, descriptions of gratitude experiences showed that central features of gratitude appeared more frequently than peripheral features, providing further evidence that the construct is characterized by a prototype structure. Studies $5 \mathrm{a}$ and $5 \mathrm{~b}$ also indicated a broader view of gratitude than that found in traditional research definitions.

In sum, the results of our studies indicated that gratitude does have a prototype structure and that laypersons conceive of gratitude much more broadly than is reflected in most current research. As a consequence, researchers might profitably consider broadening the definition of gratitude that has informed their research or tailor their measures to investigate particular aspects of gratitude.

\section{APPENDIX A}

\section{Central Condition}

Liz had been busy writing her term paper for the last several weeks. She spent hours in the library looking up references, thinking of how to best express her ideas, and proofreading to make sure everything was just right. On the night before the paper was due, while she was making a few final changes, her computer crashed and she lost everything. Liz panicked and then called her neighbor Jim, who came right over and was up all night fixing her computer, and got it fixed just in time for her to turn it in on time. When she thought of Jim she got a warm feeling, a sincere feeling of appreciation. The next time Liz saw Jim, she gave him a bug and said, "thank you." (For the peripheral terms of this condition we inputted satisfaction, indebtedness, desire to reciprocate, obligated, and send a card, respectively, in place of the italicized words.)
APPENDIX A (continued))

\section{Peripheral Condition}

Lydia had just gone through a very difficult semester, and was feeling very stressed. In order to relax, she retreated back into a beautiful wooded area right next to the ocean. At first she stewed about her problems, but then she looked around at the breathtaking scenery around her and felt lucky and a sense of awareness. She thought of her outstanding opportunities, which brought her enthusiasm and helped her self-esteem. Something about this special place always made her feel better. (For the central terms of this condition we inputted humbled, thankful, family, happy feeling, and smile, respectively, in place of the italicized words.)

\section{APPENDIX B}

\section{Central Condition}

Jim was sitting at his graduation ceremonies and began thinking of all the people that had assisted him in getting where he was today and felt a surge of love and appreciation come over him, and whispered an inaudible "thank you" as he looked across the room at these people. This feeling he had was a warm feeling triggered by the kindness of others. (For the peripheral terms of this condition we inputted luck and emotion, prayer, peacefulness, and awareness, respectively, in place of the italicized words.)

\section{Peripheral Condition}

Ann was waiting for her boyfriend to meet up with her at their favorite restaurant for dinner and she was starting to wonder if he had forgotten about it. It was the celebration for their one-year anniversary and she began to feel irritated that he could possibly forget their planned dinner appointment. Then, suddenly, John popped through the door to where the cooks worked, and accompanied by several waiters, he began to serenade her with their favorite song. Immediately after the song, the waiters served Ann her favorite dish and John presented her with a dozen roses. Ann felt a sense of calm awareness sweep over her as she thought of John's deed. It was a pleasant feeling and she felt satisfied. (For the central terms of this condition we inputted thankful, appreciation, considerate, happy feeling, and honored, respectively, in place of the italicized words.)

\section{NOTE}

1. Unless it affected the pattern of results, sex was excluded from analyses reported in subsequent studies.

\section{REFERENCES}

Adler, M. G., \& Fagley, N. S. (2005). Appreciation: Individual differences in finding value and meaning as a unique predictor of subjective well-being. Journal of Personality, 73, 79-114. 
Andersson, L. M., Giacalone, R. A., \& Jurkiewicz, C. L. (2007). On the relationship of hope and gratitude to corporate social responsibility. Journal of Business Ethics, 70, 401-409.

Bryant, F. B., \& Veroff, J. (2007). Savoring: A new model of positive experience. Mahwah, NJ: Lawrence Erlbaum.

Cantor, N., \& Mischel, W. (1979). Prototypicality and personality: Effects on free recall and personality impressions. Journal of Research in Personality, 13, 187-205.

Dean, L. R., Carroll, J. S., \& Yang, C. (2007). Materialism, perceived financial problems, and marital satisfaction. Family and Consumer Sciences Research Journal, 35, 260-281.

Emmons, R. A. (2004). An introduction. In R. A. Emmons \& M. E. McCullough (Eds.), The psychology of gratitude (pp. 3-16). New York: Oxford University Press.

Emmons, R. A., \& McCullough, M. E. (2003). Counting blessings versus burdens: An experimental investigation of gratitude and subjective well-being in daily life. Journal of Personality and Social Psychology, 84, 377-389.

Emmons, R. A., \& McCullough, M. E. (Eds.). (2004). The psychology of gratitude. New York: Oxford University Press.

Emmons, R. A., McCullough, M. E., \& Tsang, J. (2003). The measurement of gratitude. In S. Lopez \& C. R. Snyder (Eds.), Handbook of positive psychology assessment (pp. 327-341). Washington, DC: American Psychological Association.

Emmons, R. A., \& Shelton, C. M. (2002). Gratitude and the science of positive psychology. In C. R. Snyder \& S. J. Lopez (Eds.), The positive psychology handbook (pp. 459-471). Oxford, UK: Oxford University Press.

Fehr, B. (1988). Prototype analysis of the concepts of love and commitment. Journal of Personality and Social Psychology, 55, 557-579.

Fehr, B. (1994). Prototype-based assessment of laypeople's views of love. Personal Relationships, 1, 309-331.

Fehr, B. (2004). Intimacy expectations in same-sex friendships: A prototype interaction-pattern model. Journal of Personality and Social Psychology, 86, 265-284.

Fehr, B., \& Russell, J. A. (1984). Concept of emotion viewed from a prototype perspective. Journal of Experimental Psychology: General, 113, 464-486.

Fehr, B., \& Russell, J. A. (1991). The concept of love viewed from a prototype perspective. Journal of Personality and Social Psychology, 60, 425-438.

Fehr, B., Russell, J. A., \& Ward, L. M. (1982). Prototypicality of emotions: A reaction time study. Bulletin of the Psychonomic Society, 20, 253-254.

Fitzgerald, P. (1998). Gratitude and justice. Ethics, 109, 119-153.

Guralnik, D. B. (1971). Webster's new world dictionary. Nashville, TN: Southwestern.

Lambert, N. M., Clark, M. S., Durtschi, J. A., Fincham, F. D., \& Graham, S. M., (2009). Benefits of expressing gratitude for the expresser: Does expressing gratitude to a partner change one's view of the relationship? Manuscript submitted for publication.

Lambert, N. M., \& Fincham, F. D. (2009). Expressing gratitude to a partner leads to more relationship maintenance behavior. Manuscript submitted for publication.
Lambert, N., Fincham, F. D., Stillman, T. L., \& Dean, L. R. (2009). More gratitude, less materialism: The mediating role of life satisfaction. Journal of Positive Psychology, 4, 32-42.

Lambert, N. M., Graham, S. M., Fincham, F. D., \& Stillman, T. F. (in press). A changed perspective: How gratitude can affect sense of coherence through positive reframing. Journal of Positive Psychology.

Masingale, A. M., Schoonover, S., Kraft, S., Burton, R., Waring, S., Fouad, B., et al. (2001, December.). Gratitude and post-traumatic symptomatology in a college sample. Paper presented at the meeting of the International Society for Traumatic Stress Studies, New Orleans, LA.

McCullough, M. E., Emmons, R. A., \& Tsang, J. (2002). The grateful disposition: A conceptual and empirical topography. Journal of Personality and Social Psychology, 82, 112-127.

McCullough, M. E., Kilpatrick, S. D., Emmons, R. A., \& Larson, D. B. (2001). Is gratitude a moral affect? Psychological Bulletin, 127, 249-266.

McCullough, M. E., \& Tsang, J. A. (2004). Parent of the virtues? The prosocial contours of gratitude. In R. A. Emmons \& M. E. McCullough (Eds.), Psychology of gratitude (pp. 123-141). New York: Oxford University Press.

Roberts, R. C. (2004). The blessings of gratitude: A conceptual analysis. In R. A. Emmons \& M. E. McCullough (Eds.), The psychology of gratitude (pp. 58-80). New York: Oxford University Press.

Rosch, E. (1975). Cognitive representations of semantic categories. Journal of Experimental Psychology: General, 104, 192-233.

Rosenberg, S., \& Jones, R. (1972). A method for investigating and representing a person's implicit theory of personality: Theodore Drieser's view of people. Journal of Personality and Social Psychology, 22, 372-386.

Rosenberg, S., \& Sedlak, A. (1972). Structural representations of perceived personality trait relationships. In A. K. Romney, R. N. Shepard, \& S. Nerlove (Eds.), Multidimensional scaling: Theory and application in the behavioral sciences (Vol. 2, pp. 133-162). New York: Seminar.

Simmel, G. (1950). The sociology of Georg Simmel. Glencoe, IL: Free Press. (Original work published 1908)

Solomon, R. C. (1977). The passions. Garden City, NY: Anchor.

Steindl-Rast, D. (2004). Gratitude as thankfulness and as gratefulness. In R. A. Emmons \& M. E. McCullough (Eds.), The psychology of gratitude (pp. 282-289). New York: Oxford University Press.

Tesser, A., Gatewood, R., \& Driver, M. (1968). Some determinants of gratitude. Journal of Personality and Social Psychology, 9, 233-236.

Watkins, P. C., Woodward, K., Stone, T., \& Kolts, R. L. (2003). Gratitude and happiness: Development of a measure of gratitude, and relationships with subjective well-being. Social Behavior and Personality, 31, 431-452.

Woodward, K. M., Moua, G. K., \& Watkins, P. C. (1998, April). Depressed individuals show less gratitude. Paper presented at the annual meeting of the Western Psychological Association, Albuquerque, NM.

Received January 25, 2008

Revision accepted March 28, 2009 